\title{
Determination of exacerbation predictors in patients with COPD in physical therapy - a longitudinal study
}

\author{
Diego M. Marino ${ }^{1}$, Kamilla T. Marrara ${ }^{1,2}$, Juliano F. Arcuri ${ }^{1}$, \\ Cecília Candolo $^{3}$, Maurício Jamami ${ }^{1}$, Valéria A. Pires Di Lorenzo ${ }^{1}$
}

\begin{abstract}
Background: Chronic obstructive pulmonary disease (COPD) typically presents the characteristic clinical condition of exacerbation, with more intense symptoms associated with greater functional loss and consequently lower chances of patient survival. Objectives: This study sought to determine the predictors of exacerbation, alone or in combination, in patients with chronic obstructive pulmonary disease (COPD) who received physical therapeutic treatment over 6 months. Method: This was an observational, longitudinal and prospective study in which 63 COPD patients residing within the municipality of São Carlos, SP, Brazil were evaluated. These patients had COPD stages II and III and were entered into a physical therapy program, consisting of 3 periods of assessment over 6 months. We evaluated the occurrence of acute exacerbation as well as the patients' body mass index (BMI), fat-free mass (FFM), fat-free mass index, forced expiratory volume in 1 second $\left(\mathrm{FEV}_{1}\right)$, dyspnea, distance walked (DW) in the 6-minute walk test (6MWT) and handgrip strength. Results: When applying Cox settings with each covariate separately, the results revealed 5\% significance only for the DW in the 6MWT, which demonstrated an interaction between BMI and FFM. Comparison of the 3 periods of assessment across the covariates measured showed a significant difference only for the DW between evaluations in the $3^{\text {rd }}$ and $6^{\text {th }}$ months. Conclusion: Upon analyzing the predictors of risk over 6 months of follow-up in patients with COPD, we found that the DW in the 6MWT was associated with the risk of exacerbation, although this risk also depended on the covariates BMI and FFM.
\end{abstract}

Keywords: COPD; physical exertion; physical therapy; survival; rehabilitation.

Clinical Trials.gov Identifier: NCT01464736

\section{HOW TO CITE THIS ARTICLE}

Marino DM, Marrara KT, Arcuri JF, Candolo C, Jamami M, Pires Di Lorenzo VA. Determination of exacerbation predictors in patients with COPD in physical therapy - a longitudinal study. Braz J Phys Ther. 2014 Mar-Apr; 18(2):127-136. http://dx.doi. org/10.1590/S1413-35552012005000146

\section{Introduction}

Chronic obstructive pulmonary disease (COPD) typically presents the clinical characteristic of exacerbation, although patients demonstrate different clinical forms and levels of severity ${ }^{1,2}$.

Exacerbation is defined as an acute increase in respiratory symptoms that exceeds normal daily variation and that leads to the need for changes in the medications regularly used by the patient, and this definition accurately describes the exacerbations related to $\mathrm{COPD}^{3}$ and/or the use of healthcare resources ${ }^{4}$. The most frequent characteristic of exacerbation is an increase in dyspnea, which requires the patient to seek medical attention ${ }^{1,2}$.

However, there is also evidence of reduced tolerance to physical efforts, and physical inactivity is more accentuated in patients with frequent exacerbations, which also makes them more susceptible to new exacerbations ${ }^{5}$.

According to Donaldson et al. ${ }^{6}$, greater numbers of exacerbations are associated with greater functional loss and, consequently, according to Cardoso ${ }^{1}$, a reduced likelihood of COPD patient survival. According to Beghé et al. ${ }^{7}$, exacerbation of COPD refers to the exacerbation of respiratory symptoms in these patients, which may or may not be related to respiratory mechanisms.

Therefore, the current study sought to identify variables, in isolation or combination, related to the occurrence of exacerbations in patients with COPD who performed a program of moderate-intensity physical exercise 2 to 3 times per week in an active manner.

\footnotetext{
${ }^{1}$ Department of Physical Therapy, Universidade Federal de São Carlos (UFSCar), São Carlos, SP, Brazil

${ }^{2}$ Department of Physical Therapy, Centro Universitário Central Paulista (UNICEP), São Carlos, SP, Brazil

${ }^{3}$ Department of Statistics, UFSCar, São Carlos, SP, Brazil

Received: 02/28/2013 Revised: 07/21/2013 Accepted: 09/19/2013
} 
In this study, an interaction between tolerance to physical efforts and the occurrence of exacerbations in COPD patients was expected. Our objective was to determine the predictors of exacerbation, in isolation or in combination, in patients with COPD who participated in moderate-intensity physical therapy treatment over 6 months.

\section{Method}

This was an observational, longitudinal and prospective study in which patients from the municipality of São Carlos, SP, Brazil, were evaluated from January 2010 to September 2011. The participants were of both genders, with a clinical diagnosis of stage II or III COPD ${ }^{3}$ and were monitored for 6 months, with evaluations at the initial time of contact, after 3 months and after 6 months.

In accordance with Resolution 196/96 of the National Health Council (Conselho Nacional de Saúde (CNS)), all of the patients signed the informed consent form after receiving guidance. The study was approved by the Research Ethics Committee of the Federal University of São Carlos (Universidade Federal de São Carlos - UFSCar), São Carlos, SP, Brazil (Opinion n ${ }^{\circ} 432 / 2008$ ).

\section{Inclusion and exclusion criteria}

The inclusion criteria consisted of patients with a clinical diagnosis of COPD, from both genders, who demonstrated a forced expiratory volume in 1 second $\left(\mathrm{FEV}_{1}\right)$ /forced vital capacity $(\mathrm{FVC})<70 \%$, with moderate to severe obstruction ${ }^{3}$, and who were ex-smokers and clinically stable at the time they were contacted.

The exclusion criteria included patients with pulmonary infections at the time of initial contact, diseases associated with cardiopathies and rheumatic and orthopedic diseases that made it impossible to perform any of the tests due to exercise limitations.

\section{Experimental procedure}

All of the patients who participated in the study were evaluated at 3 times points (every 3 months) for 6 months. First, an initial contact was scheduled with the patient, during which they were invited to participate in the study after the research objectives were explained.

The patients were placed in a physical therapy program, consisting of 2 to 3 sessions per week, for a period of 3 months. The program consisted of aerobic physical training on a rolling treadmill or bicycle ergometer for at least 20 minutes with an intensity of $80 \%$ of the velocity and the slope obtained in the incremental, symptom-limited cardiopulmonary exercise test (CPT). The intensity of the training was constantly adjusted ${ }^{8}$ to maintain the sensation of dyspnea between 4-6 on the BORG-CR10 scale, always respecting a heart rate that was $85 \%$ of the maximum heart rate.

The physical therapy program also involved guidelines for respiratory exercises ${ }^{8}$, free exercises with the upper limbs (UULL) and lower limbs (LLLL) and stretching the muscles of the neck, trunk, UULL and LLLL ${ }^{3}$; bronchial hygiene maneuvers were administered only when necessary.

In all of the evaluations, the patients were subjected to a general and specific evaluation consisting of the following: identification of the occurrence of exacerbation; anthropometric evaluation; verification of body composition according to the body mass index (BMI), fat free mass (FFM) and fat free mass index (FFMI); obstruction of the airways, as evaluated by spirometry through the $\mathrm{FEV}_{1}$, dyspnea by the Modified Medical Research Council (mMRC) scale, tolerance to physical efforts by the distance walked (DW) in the 6-minute walk test (6MWT) and evaluation of hand grip strength.

\section{Evaluation of exacerbation}

The exacerbation of COPD was carefully evaluated in this study according to the appearance or worsening of more than 2 signs and/or symptoms (dyspnea, sputum purulence or sputum volume, coughing or wheezing) for more than 2 consecutive days.

The occurrence as well as the number of exacerbations after the first evaluation was questioned at the second evaluation period ( $3^{\text {rd }}$ month) as well as the third period ( $6^{\text {th }}$ month). In addition, when present, exacerbation of the clinical status during the corresponding period was evaluated, which was characterized by sustained worsening of the health condition of patients who required an unscheduled visit to a healthcare facility, such as the emergency room, a basic healthcare unit or the responsible pulmonologist. The number of patients who quit the study was also recorded over the 6-month period.

\section{Anthropometrics}

The measurements of weight and height were verified using a biometric scale (Welmy ${ }^{\circledR}$, model 110FF, São Paulo, SP, Brazil) on which the patients stood barefoot and semi-clothed, in the erect position with the head aligned. 
The BMI was calculated according to the method of Willett ${ }^{9}$ using the following classification system: $\mathrm{BMI}<20 \mathrm{Kg} / \mathrm{m}^{2}$ was considered low weight; BMI between 20 and $24.9 \mathrm{Kg} / \mathrm{m}^{2}$ as normal weight; BMI between 25 and $29.9 \mathrm{Kg} / \mathrm{m}^{2}$ as overweight and BMI $\geq 30 \mathrm{Kg} / \mathrm{m}^{2}$ as obese ${ }^{10}$.

\section{Body composition}

Additionally, the FFM was verified by bioelectrical impedance analysis (BIA) at $50 \mathrm{kHz}$ on a digital scale (Ironman, Tanita ${ }^{\circledR}$ model BC-553, Illinois, USA), according to the manufacturer's recommendations. The patients were directed to fast for 3 hours prior to testing.

For the FFMI analysis, the formula described by Steiner et al. ${ }^{11}$ was used, and FFMI = fat free mass/ height $^{2}$.

\section{Spirometry}

Spirometry was performed by the responsible pulmonologist before and after the use of a bronchodilator to verify the degree of obstruction, considering the ratio $\mathrm{FEV}_{1} / \mathrm{FVC}<70 \%$ and $\mathrm{FEV}_{1}$. The patients were then classified as having stage II obstruction $\left(50 \% \leq \mathrm{FEV}_{1}<80 \%\right.$ of the predicted) or stage III obstruction $\left(30 \% \leq \mathrm{FEV}_{1}<50 \%\right.$ of the predicted $)^{3}$.

\section{Dyspnea}

Evaluation of the degree of dyspnea was performed using the mMRC scale ${ }^{12}$. This scale is based on the degrees of different activities that lead to dyspnea, varying between " 0 " (individual is not bothered by a lack of air except when subjected to vigorous exercise) to "4" (individual presents with a significant lack of air from leaving their home or even from changing clothes).

The patients determined the number on the scale that best related to their dyspnea during an interview applied by the same examiner.

\section{Tolerance to physical effort}

Tolerance to physical effort was evaluated according to the DW in the 6MWT. This test was performed in a flat corridor, 30 meters in length, according to the standardized method of the American Thoracic Society (ATS) ${ }^{13}$. The DW was recorded at the end in meters ${ }^{14}$.

For the calculation of the predicted distance, the formula (predicted distance $\left.{ }_{\mathrm{m}}\right)=622.461-(1.846 *$ age $\left._{\text {years }}\right)+\left(61.503 *{ }_{1}\right)^{15}$ was used, with knowledge of the age of the evaluated patients.

\section{Handgrip strength}

Handgrip strength evaluations were performed on the dominant upper limb using a Jamar ${ }^{\circledR}$ dynamometer (Jackson, MI 49203 USA), which provided measurements in kilograms-force $(\mathrm{kgf})^{16}$ and was adjusted to the second position. The patients remained seated, with their elbow flexed at $90^{\circ}$ and their forearm and wrist in a neutral position, according to the standardized method proposed by the American Society of Hand Therapists (ASHT).

Three maximum voluntary contractions were requested with a rest of 30 seconds between contractions, and the average of the values obtained was considered for statistical analysis. These measurements did not vary by more than $5 \%$.

\section{Data analysis}

The Shapiro-Wilk test was performed to verify the normality of the data, with verification of a non-parametric distribution. Descriptive statistics were performed for sample characterization, and the data were expressed as the median and interquartile interval and presented in tables and figures.

Regarding the initial analysis of the risk of exacerbation, non-parametric analysis of time until exacerbation was performed using the construction of a survival curve to exacerbation. The KaplanMeier ${ }^{17}$ estimator and $95 \%$ confidence intervals were also used.

The influence of BMI, FFM, FFMI, FEV ${ }_{1}$, dyspnea, DW in the 6MWT and handgrip strength as predictors of exacerbation was verified through the adjustment of the Cox model, and patients who experienced exacerbation were excluded from the sample for the statistical analysis.

The Cox model permitted data analysis according to period of life, in which the response in a certain period was evaluated until the occurrence of an event of interest (exacerbation), after adjusting for covariates ${ }^{17}$. In this study, the period of life between the evaluation and the exacerbation of the patients was adjusted for the covariates cited above and their interactions. The selection of covariates was conducted according to the proposal cited by Colosimo and $\mathrm{Giolo}^{17}$, and the relative risks involving the covariates of the final model were calculated. The relative risk in the Cox model was calculated by the exponential of the coefficient of the covariate under consideration. 
With the objective of comparing the 3 periods of evaluation for each covariate, the Friedman test followed by the post-hoc Dunn test was selected.

For comparisons between the 3 evaluation periods, the GraphPad InStat for Windows application was used. The analyses and figures presented were obtained using the $\mathrm{R}$ statistical software (free software) and the SAS 9.3 software (SAS/STAT, Version 9.3 of the SAS System for Windows). The hazard ratio (HR) was also calculated, and the $95 \%$ confidence interval (CI) was used. The significance level adopted was $\mathrm{p}<0.05$.

\section{Results}

Considering the entire study period, 63 patients were initially recruited. However, 12 patients participated only in the first evaluation, making it impossible to monitor them over the 6-month period due to personal problems (4), abandonment (6), fall (1) and surgery (1). Of the 51 patients who remained in the study, 20 showed stage II obstruction and 31 stage III obstruction. Four presented exacerbation in the first 3 months of monitoring and, of the 47 patients who continued, 13 showed exacerbation between the $3^{\text {rd }}$ and $6^{\text {th }}$ months of monitoring, and 5 abandoned the study for personal problems (4) or surgery (1), as shown in Figure 1. There was no occurrence of death over the 6-month monitoring period.
The anthropometric, spirometry, dyspnea, DW in the 6MWT, predicted distance in the 6MWT and handgrip strength characteristics for the patients included in this study are shown in Table 1.

Upon applying adjustments to the Cox model for each of the covariates separately, a significance of $5 \%$ was observed for only the DW in the 6MWT $(\mathrm{p}=0.02)$, which demonstrated an interaction between the DW in the 6MWT with BMI $(\mathrm{p}=0.01)$ and FFM $(\mathrm{p}=0.01)$.

Based on information in the literature ${ }^{18}$ and the values obtained for the first and third quartiles of the sample, respectively, the following median values were measured for the DW in the 6MWT: 357,340 and $500 \mathrm{~m}$. These results highlight the large variation observed in this study for this variable.

Values of 23 and $25 \mathrm{~kg} / \mathrm{m}^{2}$ were considered for BMI and values of 43 and $46 \mathrm{~kg}$ were considered for FFM, taking into consideration the greater frequency of these values in the sample included in this study.

Considering a BMI of $23 \mathrm{~kg} / \mathrm{m}^{2}$ and an FFM of $43 \mathrm{~kg}$, the risk of exacerbation in patients with a DW of $357 \mathrm{~m}$ in the 6MWT was approximately 0.3 times less than the risk of exacerbation for patients with a DW of $340 \mathrm{~m}$. Moreover, upon increasing the DW to $500 \mathrm{~m}$, the risk of exacerbation was 0.95 times less (Figure 2A).

After evaluating the FFM at $46 \mathrm{~kg}$, and maintaining the same BMI value, the risk of exacerbation among

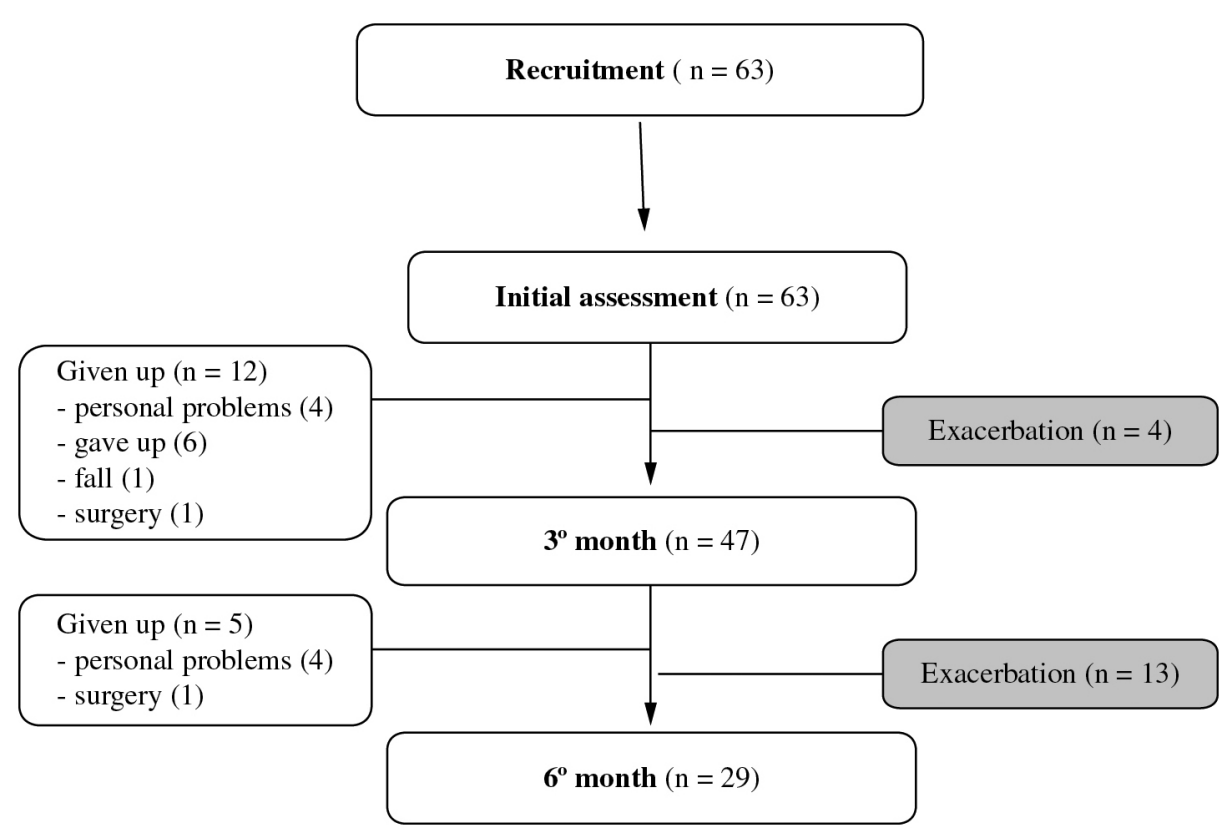

Figure 1. Flowchart of the study design. 
patients who walked $357 \mathrm{~m}$ in the 6MWT was approximately 0.21 times lower than the risk of exacerbation for patients with a DW of $340 \mathrm{~m}$. In addition, by increasing the DW to $500 \mathrm{~m}$, this risk was approximately 0.89 times lower; in other words, this risk was reduced by approximately $90 \%$ (Figure $2 \mathrm{~B}$ ).

With a BMI of $25 \mathrm{~kg} / \mathrm{m}^{2}$ and FFM of $43 \mathrm{~kg}$, the risk of exacerbation for patients who walked $357 \mathrm{~m}$ in the 6MWT was 0.37 times less compared to patients who walked $340 \mathrm{~m}$. In comparison, after walking $500 \mathrm{~m}$, this risk was approximately 0.99 times lower; in other words, this risk was reduced by $99 \%$, as illustrated in Figure 3A. With maintenance of the BMI and a FFM of $46 \mathrm{~kg}$, the risk of exacerbation was approximately 0.32 times less in patients who walked $357 \mathrm{~m}$ in the 6MWT compared to patients who walked $340 \mathrm{~m}$; with the increase of the DW to $500 \mathrm{~m}$, this risk was 0.97 times lower (Figure 3B).

Table 2 shows the values for the covariates of body composition, airway obstruction, dyspnea, DW in the 6MWT and handgrip strength in the 3 described evaluations, demonstrating significant differences only for the DW between the 3- and 6-month evaluations.

Table 1. Anthropometric characteristics, spirometry, dyspnea, distance walked and predicted distance in the 6MWT and handgrip strength of the studied patients $(n=63)$.

\begin{tabular}{cc}
\hline Variables & $\begin{array}{c}\text { Median } \\
\text { (interquartile interval) }\end{array}$ \\
Age (years) & $71(62-75)$ \\
Weight $(\mathrm{kg})$ & $66(56-76)$ \\
Height $(\mathrm{m})$ & $168(164-171)$ \\
BMI $\left(\mathrm{kg} / \mathrm{m}^{2}\right)$ & $24(21.5-25.6)$ \\
Fat-free mass $(\mathrm{kg})$ & $46(43.2-48.3)$ \\
Fat-free mass index $\left(\mathrm{kg} / \mathrm{m}^{2}\right)$ & $17(15.1-18.9)$ \\
FEV $(\%$ predict $)$ & $47(37.8-64.5)$ \\
FVC $(\%$ predict $)$ & $76.5(66.5-85)$ \\
FEV $/$ FVC $(\%)$ & $63(49-65.6)$ \\
MVV $(\%$ predict $)$ & $43.6(36.9-57.7)$ \\
Dyspnea (mMRC) & $2(1-2)$ \\
Distance walked in 6MWT (m) & $466(349-503)$ \\
Predict distance in 6MWT (m) & $554.7(545.5-571.4)$ \\
Handgrip strength $(\mathrm{kgf})$ & $38(34.7-40)$ \\
\hline
\end{tabular}

Data reported for the median (interquartile interval). BMI: body mass index. $\mathrm{FEV}_{1}$ : forced expiratory volume in one second. FVC: Forced Vital Capacity. MVV: maximum voluntary ventilation 6MWT: six-minute walk test.

\section{Discussion}

\section{Principal findings}

The principal finding of this study was that the DW in the 6MWT, in association with BMI and FFM, predicted the risk of exacerbation among COPD patients monitored over a 6-month period. Additionally, a reduction was observed in the tolerance to physical efforts over 6 months of monitoring relative to the $3^{\text {rd }}$ month.

\section{Importance of this study}

Because few data have been reported in the literature concerning the evaluation of DW in the 6MWT as a predictor of exacerbation ${ }^{18}$ in COPD patients enrolled in an exercise program, this study contributes to the field by showing that the evaluation of DW in the 6MWT could be used to predict the risk of exacerbation, while also taking into consideration BMI and FFM.

During exacerbation of COPD and even after its occurrence, there is a decrease in tolerance to physical efforts, and a certain percentage of patients with COPD do not recuperate even 3 months after the occurrence of exacerbation ${ }^{19}$. This finding most likely justifies the results observed in this study with regard to the reduction of DW in the 6MWT, even among patients undergoing physical therapy.

Because of the interaction between DW and body composition variables, it is important to include a range of variables in the evaluation and monitoring of these patients in an attempt to heed guidelines and referrals considering the occurrence of exacerbations.

\section{DW, BMI and FFM as determinants of exacerbation in COPD}

This study demonstrated that the DW in the 6MWT, in association with BMI and FFM, could predict the risk of exacerbation in patients with COPD. In addition, there is evidence of the association between body mass and mortality in patients with COPD, which highlights this variable as an important extrapulmonary factor that may signal the need for disease intervention ${ }^{20}$. Additionally, a relationship was also previously observed between body mass and acute exacerbation in COPD, accompanied with the imbalance generated by a decrease in food ingestion and an increase in the energy used by the patient ${ }^{21}$.

Slinde et al. ${ }^{22}$ and Vestbo et al. ${ }^{23}$ reported that free fat mass was related to mortality in COPD; however, its impact on functional limitation remains unknown. According to some authors ${ }^{23}$, BMI is an 

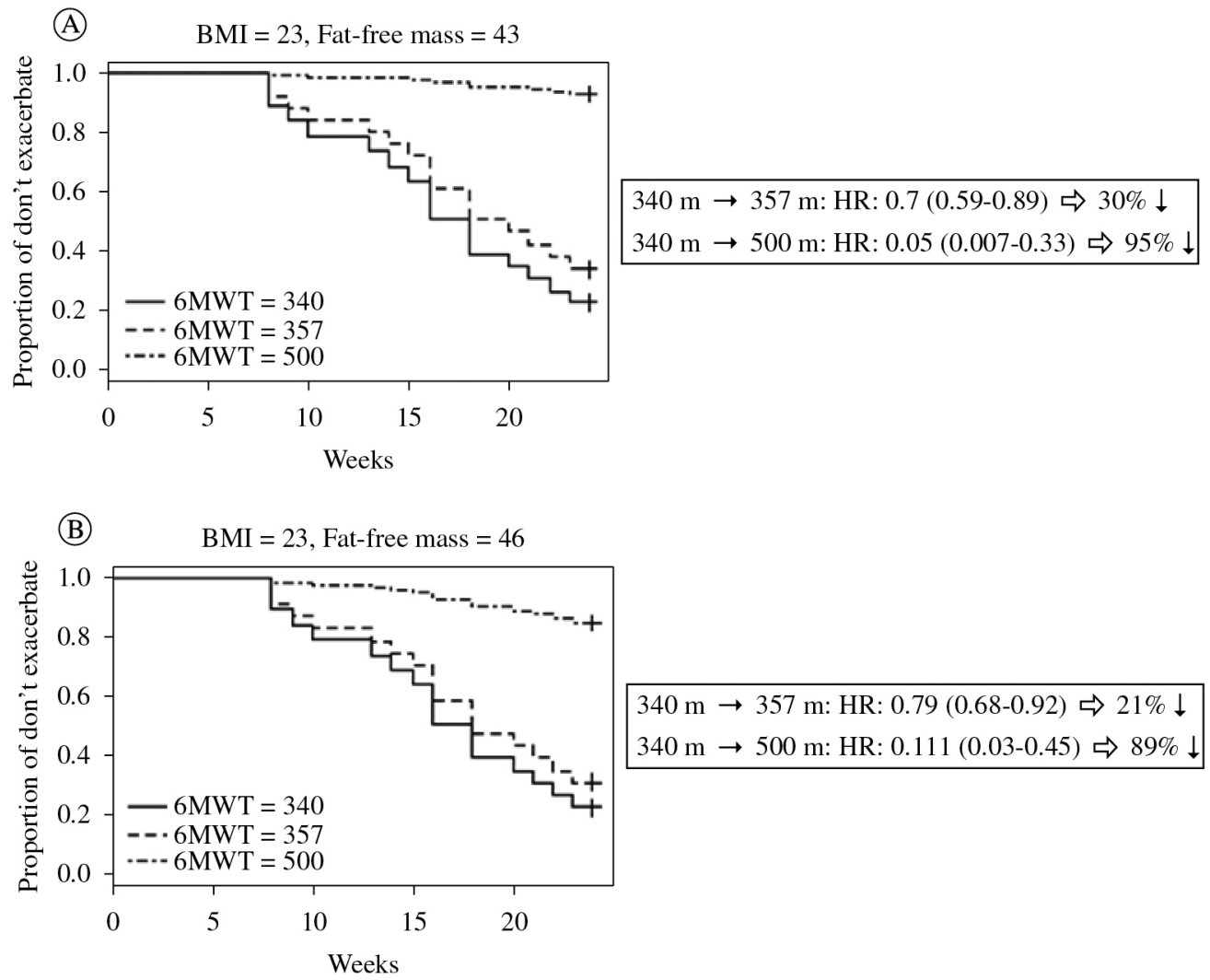

Figure 2. Proportion of exacerbations considering variations in the DW in the 6MWT and the interaction with the fixed value of BMI $\left(23 \mathrm{~kg} / \mathrm{m}^{2}\right)$ and FFM of $43 \mathrm{~kg}(\mathrm{~A})$ and $46 \mathrm{~kg}(\mathrm{~B})$. Data are expressed as the HR: hazard ratio and CI: confidence interval (95\%).

Table 2. Corporal composition, air way obstruction, dyspnea, distance walked in 6MWT and handgrip strength of patients over the six months of follow-up.

\begin{tabular}{cccc}
\hline Variables & Initial assessment $(\mathbf{n}=\mathbf{6 3})$ & $\mathbf{3}^{\mathbf{0}}$ month $(\mathbf{n}=\mathbf{4 7})$ & $\mathbf{6}^{\mathbf{0}}$ month $(\mathbf{n}=\mathbf{2 9})$ \\
BMI $\left(\mathrm{kg} / \mathrm{m}^{2}\right)$ & $24(21.5-25.6)$ & $22.5(20.7-25.5)$ & $22.3(20.8-26.1)$ \\
Fat-free mass $(\mathrm{kg})$ & $46(43.2-48.3)$ & $45.4(43.5-48.6)$ & $45.4(43.6-48.1)$ \\
Fat-free mass index $\left(\mathrm{kg} / \mathrm{m}^{2}\right)$ & $17(15.1-18.9)$ & $16.7(15.8-17.2)$ & $16.3(16.1-17.3)$ \\
FEV $_{1}(\%$ predict $)$ & $47(37.8-64.5)$ & $46.8(37.2-58.4)$ & $47.8(37.8-66.1)$ \\
Dyspnea (mMRC) & $2(1-2)$ & $2(1.5-2)$ & $2(1-2)$ \\
Distance walked in 6MWT (m) & $466(349-503)$ & $470(349-537)$ & $402(252-486)^{*}$ \\
Handgrip strength (kgf) & $38(34.7-40)$ & $37.3(34.8-39)$ & $37.3(33.4-40)$ \\
\hline
\end{tabular}

Data reported for the median (interquartile interval). BMI: body mass index. $\mathrm{FEV}_{1}$ : forced expiratory volume in one second. 6MWT: six-minute walk test. Friedman Test with Dunn post-hoc: ${ }^{*} \mathrm{p}<0.05$ versus $3^{\circ}$ month.

independent factor for prognosis in this disease, with reduced body mass associated with an increase in mortality. According to Lan et al. ${ }^{24}$, low BMI exerts an influence on COPD, independent of the degree of airway obstruction. Furthermore, it is worth reporting that age, physical inactivity, hypoxia and the use of medications, primarily corticoids, was also shown to influence weight loss and the decrease in $\mathrm{FFM}^{25}$.

According to Schols et al. ${ }^{26}$, in addition to FFM serving as a predictor of mortality, this variable can be used for the staging of COPD because it acts as a systemic marker of disease severity. 
(A)

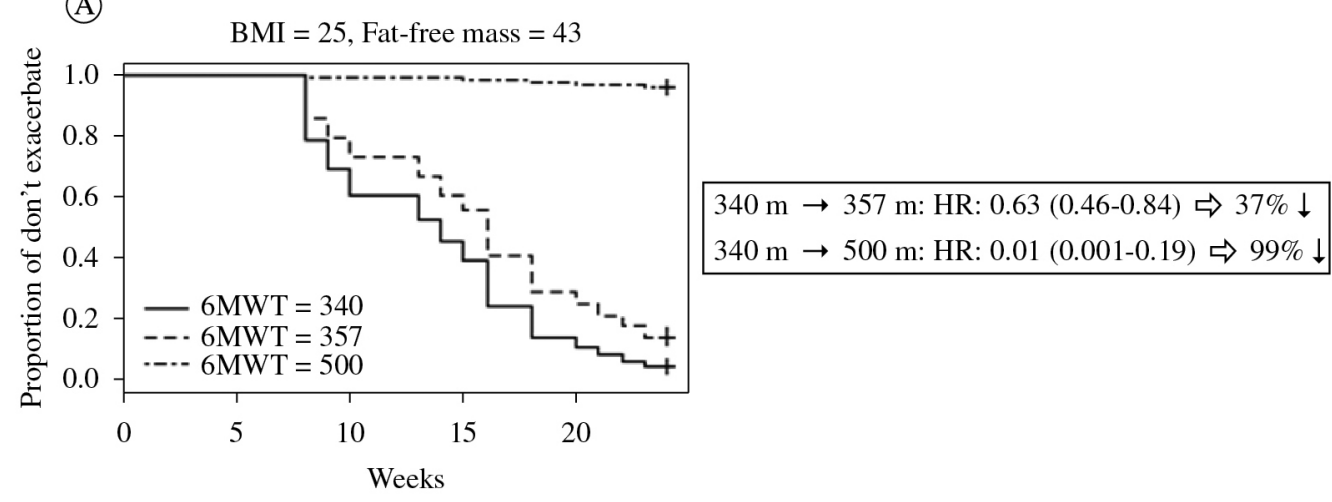

(B)

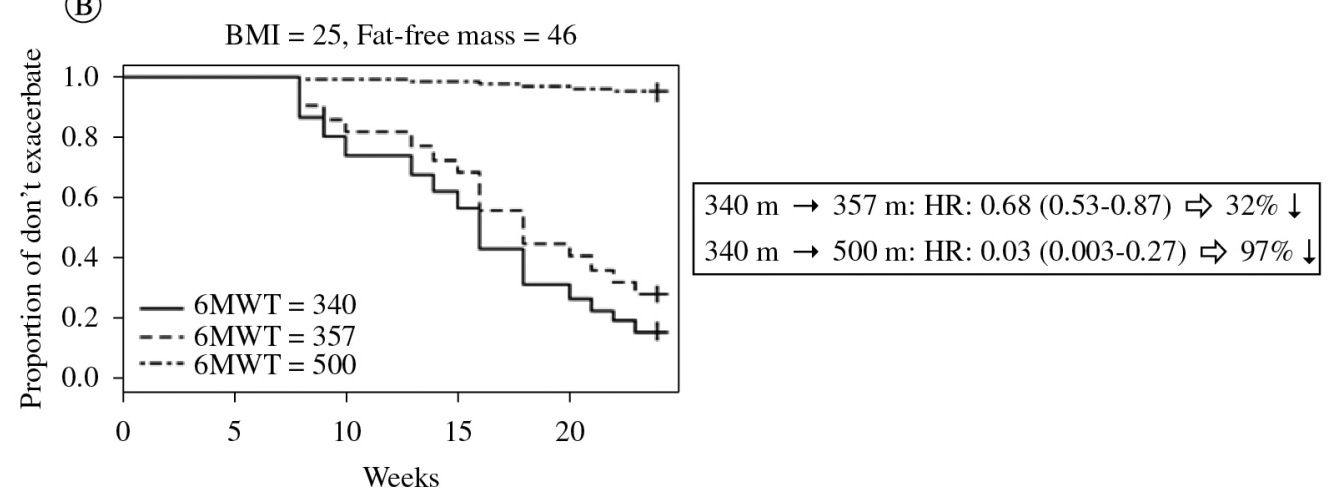

Figure 3. Proportion of exacerbations considering variations in the DW in the 6MWT and the interaction with the fixed value of BMI $\left(25 \mathrm{~kg} / \mathrm{m}^{2}\right)$ and FFM of $43 \mathrm{~kg}(\mathrm{~A})$ and $46 \mathrm{~kg}(\mathrm{~B})$. Data are expressed as the HR: hazard ratio and CI: confidence interval (95\%).

This study found that tolerance to exercise, as evaluated by the DW in the 6MWT, was shown to predict the risk of exacerbation in patients with COPD, provided that there was an association with BMI and FFM. According to Celli ${ }^{27}$, the capacity to perform exercise is one of the most important variables to be considered in the prognosis of COPD, as tolerance to physical effort shows a progressive decline and functionality is generally decreased with disease progression.

Anzueto ${ }^{28}$ reported that the reduction in physical activity could be demonstrated by the decrease in DW in the 6MWT, resulting in a higher probability of new exacerbations and hospitalizations ${ }^{3,29}$. Similarly, according to Rondelli et al. ${ }^{30}$, intolerance to physical effort is one characteristic of individuals with COPD, which is related to progressive incapacity, with a consequent reduction in survival.

According to Enright et al..$^{31}$ and Pinto-Plata et al..$^{32}$, DW appears to be a good predictor of mortality because it reflects not only respiratory function but also cardiopulmonary and peripheral muscular system function, in addition to relating to other important outcomes in patients with COPD, such as dyspnea ${ }^{31}$.

Kessler et al. ${ }^{33}$ and Carr et al. ${ }^{34}$ observed that patients with COPD after exacerbation show a reduction in DW in the 6MWT. The former study showed that the increased risk of hospitalization among these patients occurred in association with DW values less than $367 \mathrm{~m}$, while in this study, it was observed that patients with episodes of exacerbation showed an average DW of $372 \mathrm{~m}$.

It is also worth reporting that, as in the present study, Carr et al. ${ }^{34}$ monitored approximately 60 patients with COPD for 6 months to verify the occurrence of exacerbation and demonstrated that the average DW in the 6MWT of patients who exacerbated was $350 \mathrm{~m}$, compared to $416 \mathrm{~m}$ for those who did not exacerbate. In the present study, the patients who did not exacerbate walked $459.9 \mathrm{~m}$ on average.

However, it should also be considered that older age is associated with a reduced DW, as reported in the study by Pires et al. ${ }^{35}$. These authors evaluated 122 individuals using the 6MWT and corroborated the 
data shown in the present study, as older patients with COPD showed lower tolerance to physical efforts.

Upon monitoring the performance of patients with COPD according to the DW in the 6MWT for 2 years, Pinto-Plata et al. ${ }^{32}$ observed a progressive increase in survival with an increase in DW. Additionally, there is evidence that a reduction of 30 meters or more in DW in the 6MWT increases the risk of death, and this therefore represents a clinically significant minimum difference in patients with COPD ${ }^{36}$.

In the present study, the risk of exacerbation, which is considered to be one of the primary causes of morbidity/mortality ${ }^{37}$, was shown to be reduced with an increase in DW. Therefore, this variable may predict the risk of exacerbation for these patients, provided there is an association with BMI that is between the reference values used in this study.

Previously, $\mathrm{FEV}_{1}$ was regarded as the variable that best represented COPD with respect to the severity of the situation and the response of the patient considering the treatment modalities ${ }^{38}$. However, O'Donnell et al. ${ }^{39}$ demonstrated that $\mathrm{FEV}_{1}$ is limited when the intent is to predict the capacity for physical efforts because it does not evaluate this condition in a systemic manner, and this finding has since been confirmed by the results of other studies. Moreover, because a decline in the DW in the 6MWT is observed among more serious patients, the DW has been shown to be a more sensitive variable for the detection of clinical changes associated with COPD as compared to the pulmonary function test, thus highlighting its importance for monitoring these patients ${ }^{40,41}$.

Fletcher and Peto ${ }^{42}$ observed a relationship between airway obstruction and survival while monitoring patients with COPD. However, $\mathrm{FEV}_{1}$ does not fully express the disease complexity and manifestations, considering that other clinical variables better predict mortality in these individuals ${ }^{27}$.

According to Vestbo et al. ${ }^{23}$ and Rabe et al. ${ }^{37}$, exacerbations in COPD are important events that influence disease severity and progression. Moreover, episodes of exacerbation result in an increase in the provision of medical care, implying a negative impact, as it is one of the primary causes of morbidity/ mortality, on patient quality of life.

The limitations of this study were that we evaluated only one convenience sample treated at only a single study center. However, the results obtained demonstrate the importance of physical exercise, specifically aerobic physical training associated with a physical therapy treatment program, for patients with COPD, as previously shown in the systematic review by Puhan et al. ${ }^{43}$. Thus, the goal for these patients is to obtain an increase and/ or maintenance in tolerance to physical efforts and a consequent reduction in the risk of exacerbation, provided that patients performed monitoring and drug treatment with the responsible pulmonologist.

\section{Conclusion}

In summary, over 6 months of monitoring of COPD patients undergoing physical therapy, we identified the DW in the 6MWT as the determinant predictor of the risk of exacerbation, although this association also depended on the covariates of BMI and FFM.

\section{References}

1. Cardoso AP. DPOC - agudização aguda - diagnosticar, prevenir e tratar. Pulmão RJ - Atualizações Temáticas. 2009;1(1):68-70.

2. Figueiredo AB, Silva SRB $F^{o}$, Lôbo RR, Moriguti JC Exacerbação da doença pulmonar obstrutiva crônica. Medicina (Ribeirão Preto). 2010;43(3):223-30.

3. Global Initiative for Chronic Obstructive Lung Disease GOLD. Global strategy for the diagnosis, management, and prevention of chronic obstructive pulmonary disease. Bethesda: Global Initiative for Chronic Obstructive Lung Disease; 2011.

4. Marchiori RC, Susin CF, Dal Lago L, Felice CD, Brandão da Silva D, Severo MD. Diagnóstico e tratamento da DPOC exacerbada na emergência. Rev AMRIGS 2010;54(2):214-23.

5. Donaldson GC, Wilkinson TMA, Hurst JR, Perera WR, Wedzicha JA. Exacerbations and time spent outdoors in chronic obstructive pulmonary disease. Am J Respir Crit Care Med. 2005;171(5):446-52. PMid:15579723. http:// dx.doi.org/10.1164/rccm.200408-1054OC

6. Donaldson GC, Seemungal TA, Bhowmik A, Wedzicha JA. Relationship between exacerbation frequency and lung function decline in chronic obstructive pulmonary disease. Thorax. 2002;57(10):847-52. PMid:12324669 PMCid:PMC1746193. http://dx.doi.org/10.1136/ thorax.57.10.847

7. Beghé B, Verduri A, Roca M, Fabbri LM. Exacerbation of respiratory symptoms in COPD patients may not be exacerbations of COPD. Eur Respir J. 2013;41(4):993-5. PMid:23543648. http://dx.doi. org/10.1183/09031936.00180812

8. Langer D, Probst VS, Pitta F, Burtin C, Hendriks E, Schans CPVD, et al. Clinical Practice Guideline for physical therapy in patients with Chronic Obstructive Pulmonary Disease (COPD) - Portuguese version. Rev Bras Fisioter. 2009;13(3):183-204. http://dx.doi.org/10.1590/ S1413-35552009005000034

9. Willett W. Nutritional epidemiology. 2th ed. Oxford: Oxford University Press; 1998. http://dx.doi.org/10.1093/ acprof:oso/9780195122978.001.0001 
10. Prescott E, Almdal T, Mikkelsenz KL, Tofteng CL, Vestbo J, Lange P. Prognostic value of weight change in chronic obstructive pulmonary disease: results from the Copenhagen City Heart Study. Eur Respir J. 2002;20(3):539-44. PMid:12358326. http://dx.doi.org/1 0.1183/09031936.02.00532002

11. Steiner MC, Barton RL, Singh SJ, Morgan MDL. Bedside methods versus dual energy X-ray absorptiometry for body composition measurement in COPD. Eur Respir J. 2002;19(4):626-31. PMid:11998990. http://dx.doi.org/10 $.1183 / 09031936.02 .00279602$

12. Mahler D, Wells C. Evaluation of clinical methods for rating dyspnea. Chest. 1988;93(3):580-6. http://dx.doi. org/10.1378/chest.93.3.580

13. ATS Statement: guidelines for the six-minute walk test. Am J Respir Crit Care Med. 2002;166(1):1117. PMid:12091180. http://dx.doi.org/10.1164/ ajrccm.166.1.at1102

14. Homann D, Stefanello JMF, Góes SM, Leite N. Impaired functional capacity and exacerbation of pain and exertion during the 6-minute walk test in women with fibromyalgia. Rev Bras Fisioter. 2011;15(6):474-80. PMid:22218712. http://dx.doi.org/10.1590/S1413-35552011000600008

15. Iwama AM, Andrade GN, Shima P, Tanni SE, Godoy I, Dourado VZ. The six-minute walk test and body weightwalk distance product in healthy Brazilian subjects. Braz J Med Biol Res. 2009;42(11):1080-5. PMid:19802464. http://dx.doi.org/10.1590/S0100-879X2009005000032

16. Figueiredo IM, Sampaio RF, Mancini MC, Silva FCM, Souza MAP. Teste de força de preensão utilizando dinamômetro Jamar. Acta Fisiatr. 2007;14(2):104-10.

17. Colosimo EA, Giolo SR. Análise de Sobrevivência Aplicada. São Paulo: Edgard Blucher; 2006.

18. Spruit MA, Polkey MI, Celli B, Edwards LD, Watkins ML, Pinto-Plata V, et al. Predicting outcomes from 6-minute walk distance in chronic obstructive pulmonary disease. $\mathrm{J}$ Am Med Dir Assoc. 2012;13(3):291-7. PMid:21778120. http://dx.doi.org/10.1016/j.jamda.2011.06.009

19. Pamplona P, Morais L. Treino de exercício na doença pulmonar crónica. Rev Port Pneumol. 2007;XIII(1):101-28.

20. Eisner MD, Blanc PD, Sidney S, Yelin EH, Lathon PV, Katz PP, et al. Body composition and functional limitation in COPD. Respir Res. 2007;8(27):7. PMid:17261190 PMCid:PMC1797017. http://dx.doi. org/10.1186/1465-9921-8-7

21. Vermeeren MA, Schols AM, Wouters EF. Effects of an acute exacerbation on nutritional and metabolic profile of patients with COPD. Eur Respir J. 1997;10:2264-9. PMid:9387951. ttp://dx.doi.org/10.1183/09031936.97. 10102264

22. Slinde F, Gronberg A, Engstrom CP, Rossander-Hulthen L, Larsson S. Body composition by bioelectrical impedance predicts mortality in chronic obstructive pulmonary disease patients. Respir Med. 2005;99(8):1004-9. http:// dx.doi.org/10.1016/j.rmed.2004.09.024

23. Vestbo J, Prescott E, Almdal T, Dahl M, Nordestgaard BG, Andersen T, et al. Body mass, fat-free body mass, and prognosis in patients with chronic obstructive pulmonary disease from a random population sample: findings from the copenhagen city heart study. Am J Respir Crit Care Med. 2006;173(1):79-83. PMid:16368793.

24. Lan CC, Su CP, Chou LL, Yang MC, Lim CS, Wu YK. Association of body mass index with exercise cardiopulmonary responses in lung function-matched patients with chronic obstructive pulmonary disease. Heart Lung. 2012;41(4):374-81. PMid:22421506. http://dx.doi. org/10.1016/j.hrtlng.2012.02.010

25. Marquis K, Debigare R, Lacasse Y, LeBlanc P, Jobin J, Carrier G, et al. Midthigh muscle cross-sectional area is a better predictor of mortality than body mass index in patients with chronic obstructive pulmonary disease. Am J Respir Crit Care Med. 2002;166:809-13. PMid:12231489. http://dx.doi.org/10.1164/rccm.2107031

26. Schols AMWJ, Broekhuizen R, Weling-Scheepers CA, Wouters EF. Body composition and mortality in chronic obstructive pulmonary disease. Am J Clin Nutr. 2005;82(1):53-9. PMid:16002800.

27. Celli BR. Predictors of mortality in COPD. Respir Med. 2010;104(6):773-9. PMid:20417082. http://dx.doi. org/10.1016/j.rmed.2009.12.017

28. Anzueto A. Impact of exacerbations on COPD. Eur Respir Rev. 2010;19(116):113-8. PMid:20956179. http://dx.doi. org/10.1183/09059180.00002610

29. Pitta F, Troosters T, Spruit MA, Probst VS, Decramer M, Gosselink R. Characteristics of physical activities in daily life in chronic obstructive pulmonary disease. Am J Respir Crit Care Med. 2005;171(9):972-7. PMid:15665324. http://dx.doi.org/10.1164/rccm.200407-855OC

30. Rondelli RR, Dal Corso S, Simões A, Malaguti C. Métodos de avaliação da fadigabilidade muscular periférica e seus determinantes energético-metabólicos na DPOC. J Bras Pneumol. 2009;35(11):1125-35. PMid:20011849. http:// dx.doi.org/10.1590/S1806-37132009001100011

31. Enright PL, McBurnie MA, Bittner V, Tracy RP, McNamara R, Arnold A, et al. The 6-min walk test: a quick measure of functional status in elderly adults. Chest. 2003;123(2):387-98. PMid:12576356. http://dx.doi. org/10.1378/chest.123.2.387

32. Pinto-Plata VM, Cote C, Cabral H, Taylor J, Celli BR. The 6-min walk distance: change over time and value as a predictor of survival in severe COPD. Eur Respir J. 2004;23(1):28-33. PMid:14738227. http://dx.doi.org/10. 1183/09031936.03.00034603

33. Kessler R, Faller M, Fourgaut G, Weitzenblum E. Predictive factors of hospitalization for acute exacerbation in a series of 64 patients with chronic obstructive pulmonary disease. Am J Respir Crit Care Med. 1999;159(1):158-64. PMid:9872834. http://dx.doi. org/10.1164/ajrccm.159.1.9803117

34. Carr SJ, Goldstein RS, Brooks D. Acute exacerbations of COPD in subjects completing pulmonary rehabilitation. Chest. 2007;132(1):127-34. PMid:17475631. http:// dx.doi.org/10.1378/chest.07-0269

35. Pires SR, Oliveira AC, Parreira VF, Britto RR. Teste de caminhada de seis minutos em diferentes faixas etárias e índices de massa corporal. Rev Bras Fisioter. 2007;11(2):147-151. http://dx.doi.org/10.1590/ S1413-35552007000200010 
36. Polkey MI, Spruit MA, Edwards LD, Watkins ML, PintoPlata V, Vestbo J, et al. Six-minute-walk test in chronic obstructive pulmonary disease minimal clinically important difference for death or hospitalization. Am J Respir Crit Care Med. 2013;187(4):382-6. PMid:23262518. http:// dx.doi.org/10.1164/rccm.201209-1596OC

37. Rabe KF, Hurd S, Anzueto A, Barnes PJ, Buist SA, Calverley $\mathrm{P}$, et al. Global strategy for the diagnosis, management, and prevention of chronic obstructive pulmonary disease: GOLD executive summary. Am J Respir Crit Care Med. 2007;176(6):532-55. PMid:17507545. http://dx.doi. org/10.1164/rccm.200703-456SO

38. Celli BR, Cote CG, Lareau SC, Meek PM. Predictors of Survival in COPD: more than just the FEV1. Respir Med. 2008;102(1):S27-35. http://dx.doi.org/10.1016/ S0954-6111(08)70005-2

39. O'Donnell DE, Lam M, Webb KA. Measurement of symptoms, lung hyperinflation, and endurance during exercise in chronic obstructive pulmonary disease. Am J Respir Crit Care Med. 1998;158(5):155765. PMid:9817708. http://dx.doi.org/10.1164/ ajrccm.158.5.9804004

40. Kuzma AM, Meli Y, Meldrum C, Jellen P, Butler-Lebair M, Koczen-Doyle D, et al. Multidisciplinary care of the patient with chronic obstructive pulmonary disease. Proc
Am Thorac Soc. 2008;5(4):567-71. PMid:18453373 PMCid:PMC2645337. http://dx.doi.org/10.1513/ pats.200708-125ET

41. Rodrigues SL, Silva CAM, Lima T, Viegas CAA, Rodrigues MP, Ribeiro FA. Influência da função pulmonar e da força muscular na capacidade funcional de portadores de doença pulmonar obstrutiva crônica. Rev Port Pneumol. 2009;15(2):199-214.

42. Fletcher C, Peto R. The natural history of chronic airflow obstruction. Br Med J. 1977;1(6077):1645-8. http://dx.doi. org/10.1136/bmj.1.6077.1645

43. Puhan MA, Gimeno-Santos E, Scharplatz M, Troosters T, Walters EH, Steurer J. Pulmonary rehabilitation following exacerbations of chronic obstructive pulmonary disease. Cochrane Database Syst Rev. 2011;(10):CD005305. PMid:21975749.

\section{Correspondence}

Diego Marmorato Marino

Rua Miguel Petroni, 4900, Condomínio Eldorado, casa 296 CEP 13563-470, São Carlos, SP, Brasil

e-mail: diego_marmorato@ hotmail.com 